\title{
Impacts of Eurasian Transport Connectivity enhancement on Russia
}

\author{
Ryuichi Shibasaki ${ }^{1}$, Hirofumi Arai ${ }^{2, *}$, and Kentaro Nishimura ${ }^{1}$ \\ ${ }^{1}$ University of Tokyo, School of Engineering, Department of System Engineering, 7-3-1, Hongo, \\ Bunkyo-ku, Tokyo, Japan \\ ${ }^{2}$ Economic Research Institute for Northeast Asia, Research Division, 5-1 Bandaijima, Chuo-ku, \\ Niigata, Japan
}

\begin{abstract}
As China has promoted the Belt and Road Initiative (BRI) since 2014 and some CIS countries including Russia established Eurasian Economic Union (EAEU) in 2015, the trans-Eurasian land transport has gained attentions. Under this background, this paper examines two questions. The first question is how significantly the recent strategic policies such as BRI and EAEU could shift container cargo from maritime shipping and land transport. The other is how much the shift could affect Russian Far East. To answer these questions, the authors estimated their impacts on cargo volume using the intermodal network simulation model. The simulation results indicate that the cargo volume shifted would be about 10 percent of the total container flows between Asia and Europe, under our assumptions. Although the land transport has potential to increase cargo volume several times as the current level, the maritime shipping will be still a dominant mode in the intercontinental cargo transport. In addition, the simulation revealed possible negative impacts on Primorye region of Russia, while the shift will advance.
\end{abstract}

\section{Background and Purpose of Study}

In recent years, we have observed strategic initiatives enhancing connectivity in the Eurasian continent. In particular, China has promoted the Belt and Road Initiative (BRI) since 2014 and some CIS countries including Russia established Eurasian Economic Union (EAEU) in 2015. These initiatives should affect international transport structure in the continent, improving railway transport connectivity and its relative competitiveness against other transport modes, including maritime shipping.

Under this background, this paper examines two questions. The first question is how significantly the recent strategic policies such as BRI and EAEU could shift container cargo from maritime shipping and land transport. The other is how much the shift could affect Russian, in particular its Far Eastern region. While examining the questions, we focus on the impact of reducing the barriers at national border crossing points (BCPs), because they are peculiar to the land transport, different from maritime and air transport and significantly affect the connectivity of the land transport.

\footnotetext{
*Corresponding author: harai@erina.or.jp
} 


\section{Recent Transport Connectivity Enhancement in Eurasia}

Even before the BRI and EAEU, there were several trans-continental transport services. In 1970's Japanese transport companies developed the Siberian Land Bridge (SLB), a multimodal container transport service between Japan and Europe, jointly together with their partners in the USSR. The key motivation was to open the shortest freight transport route from Japan to Europe taking the advantage of existing infrastructure of the Trans-Siberian Railway (TSR). After a long slump in the last decade of 20th century, the number of international container through the TSR has tended to grow, reaching to 771 thousand TEU (twenty-foot equivalent units) in 2017 [1], whereas the number was merely 72 thousand TEU in 1999 [2].

The China Land Bridge (CLB) service was developed with the similar concept as the SLB in 1990's. Instead of the Far Eastern Russian ports for the SLB, the CLB planned to use Chinese ports, such as Lianyungang. Originally, the CLB targeted the transit containers from Japan and ROK through the Chinese territory and the China-Kazakhstan border to the central and western part of the Eurasian continent. In practice, however, it had been a minor transport route to Central Asia.

The number of container crossing the China-Kazakhstan border started to grow, when the first train heading to Duisburg launched from Chongqing in March 2011. The motivation of the new train service is to develop an alternative land transport route to Europe beside the existing maritime shipping routes through Chinese seaports, Indian Ocean and Suez Canal. Eventually, the block train between China and Europe obtained a new brand name; China Railway Express (CRE), which gave a new impact to the transEurasian transport. The announcement of the Silk Road Economic Belt concept by President Xi Jinping in the fall of 2013 spurred use of the CRE. In addition, the Eurasian Customs Union, which inaugurated on 1st of January 2010 and became a part of the EAEU after its establishment on 1st of January 2015, provided with a favorable condition for the CRE, ensuring simplified cross-border customs formalities at BCPs between Kazakhstan, Russia and Belarus.

As a result, the number of transported containers by the CRE service has grown in 150 times from 1.4 thousand TEU in 2011 to 212 thousand TEU in 2017 [3]. The sharp growth of the CRE contributes to the above-mentioned increase of the international container transport of the TSR, as aside from a small number or test trains, all regular rail connections between China and the EU have so far been carried out via the trans-Siberian routes [4]. In this context, Russia gains benefits from the CRE and the BRI of China. In other words, as Jakub Jakóbowski et.al argue, as far as the development of the transSiberian corridors is concerned, Beijing's strategies are convergent with the interests of Russia [4].

Thus, the recent strategic initiatives, such as the BRI and EAEU, and transport connectivity improvement thereof, positively affect Russia, thanks to the shift from maritime shipping to railway transport. A problem is that the impact on Russia may be uneven across its huge territory. Far Eastern Russia, in particular, may lose certain portion of the container traffic that goes through local ports currently because of the shift.

In order to investigate this problem, we have to address a more fundamental issue, i.e. quantitative assessment of the magnitude of the modal shift, as discussed in the following sections.

\section{Method of Analysis}

In this paper, the authors apply a two-layered network assignment model (NAM) in order to assess impact of the strategic initiatives on the change of cargo flow quantitatively, 
assuming that the initiatives can be interpreted into several policy measures aiming at encouraging the use of land transport. They are incorporated in the simulation model, as changes of parameters. The size of impact is examined by changes of cargo volume at Chinese border crossing points (BCPs) and seaports.

\subsection{Model}

The simulation model used in this paper have developed earlier by the authors from the perspective of shippers, covering the Eurasian continent including China, Russia, Mongolia and Central Asia ([5-7]). The model consists of a super-network for intermodal shipping in the upper layer and two real networks representing each maritime shipping (MS) and hinterland shipping (HS) network in the lower layer.

The super-network model in the upper layer includes the outputs of the real network submodels in the lower layer, namely ocean freight charge and shipping time for the MS and LT networks. The maritime and land cargo shipping demands, which are the inputs of the two submodels in the lower layer, are cargo flows of the MS and LT link in the supernetwork model. The reason why the model is divided into two layers is the consideration of the freight charge, which differs from the shipping cost and is estimated by reference to the path-based, rather than link-based, shipping cost to better reflect reality. Therefore, the different layered networks are necessary to compute both freight charge and shipping cost.

The model covers the global liner shipping network formed by the major shipping companies. In principle, all container ports whose annual international throughput was more than 500,000 TEU as of 2013 (including empty containers but excluding domestic containers) are included. Additionally, the model includes several gateway seaports (such as Vostochny in Russia, Poti in Georgia and Riga in Latvia) across the Eurasian continent that are not included in the list; thus the total number of container ports considered in the model is 187. The MS network is developed based on the MDS containership databank data. Because the model focuses on container flow in the global liner service network and the transshipment of containers at hub ports, some services provided by smaller local companies are eliminated from the network for computational simplicity. The LT network covers 24 countries in the Eurasian continent (i.e. Afghanistan, Armenia, Azerbaijan, Belarus, China, Estonia, Georgia, Germany, Iran, Kazakhstan, Kyrgyz, Latvia, Lithuania, Moldova, Mongolia, the Netherlands, Pakistan, Poland, Russia, Tajikistan, Turkey, Turkmenistan, Ukraine and Uzbekistan).

The shipping demand for container cargo (container OD cargo) is fixed at the 2013 year level, obtained by estimation using various existing data sources, including World Trade Service (WTS) data provided by IHS, Inc.. Since this study mainly focuses on route competitions of international maritime containers and their relevant cargo, only maritime containers and 'container-equivalent' land cargo are considered in the model simulation. The OD cargo is made on a TEU (twenty-foot equivalent unit) basis.

The model shows good performance in replication of the current transport pattern in both modal split between maritime and land transport and container throughput at each port [7].

\subsection{Policy Scenarios for Simulation}

The authors prepare four scenarios in addition to a baseline scenario, as described in Table 1. Note that the baseline scenario does not replicate the current situation, but replicates the situation before launching the CRE in 2014, when there were no discounts on tail freight charge. Some of the current promotion measures of the CRE are included in the scenario S1. For example, for reflecting the subsidies provided by Chinese regional governments, rail 
freight charge for the cargo dispatched from and arriving at China is discounted by 50 percent of the original amount. In addition, average rail speed and frequencies in the countries along the CRE (i.e. China, Russia, Mongolia and Kazakhstan) is doubled to reflect the recent practices that CRE trains run from China to Europe in around two weeks.

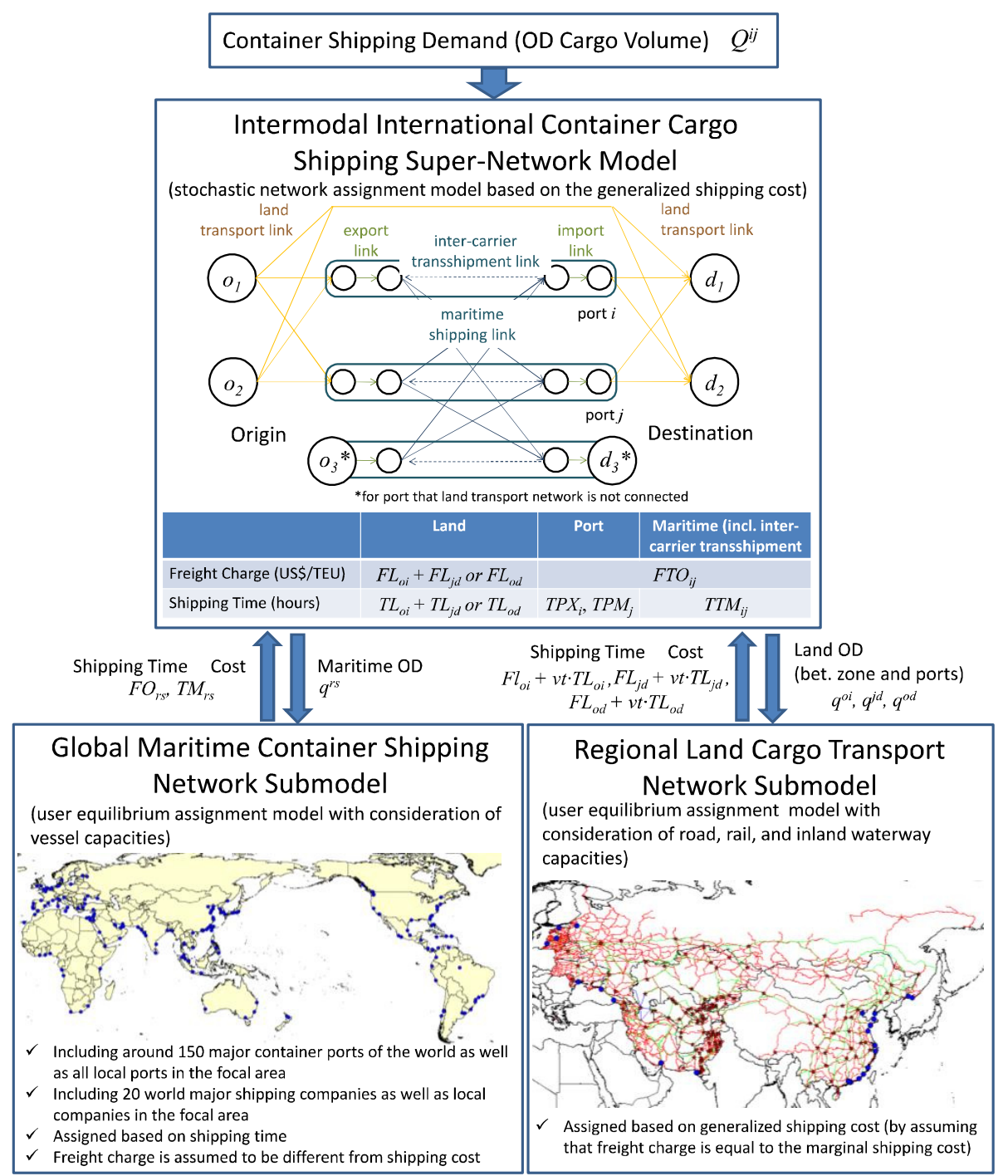

Fig. 1. Model structure. Source: [7].

The scenario S-2 is introduced to examine an effect of cross-border facilitation. In the base case, a coefficient on the border barrier at China is set higher than the standard level in the Eurasian continent, considering that its rail gauge $(1,435 \mathrm{~mm})$ is different from the neighboring Russia, Mongolia and Kazakhstan $(1,520 \mathrm{~mm})$ and that it had not been a member country of TIR convention until 2018. The coefficient on Chinese border is assumed to reduce at the standard level in the Eurasian continent in the scenario S-2. Subsequent scenarios (S-3 and S-4) assume more discounts on rail freight charge than that in the S-1 and S-2 scenarios, respectively. 
In all cases, throughput capacity is upgraded by increasing service frequency so that it should not limit the potential freight flow generated by the promotion measures.

Table 1. Assumed CRE promotion measures by scenario.

\begin{tabular}{|c|c|}
\hline Scenario & Assumptions \\
\hline Base & Without any promotion measures (i.e. Replication of the situation before the \\
CRE)
\end{tabular}

\section{Simulations Results}

\subsection{Impact of the CRE Promotion Measures on Land Transport Volume}

Figure 2 shows the container cargo volume to transit Chinese BCPs in the baseline scenario and the scenarios S-1 to S-4. The volume at the BCPs of Primorye, Manzhouli BCP and the BCPs with Kazakhstan increases as the promotion measures advance. In particular, Manzhouli BCP and the BCPs with Kazakhstan gain much more cargo in case where the discount rate of freight charge is large (compare the results between S-1 and S-3 and between S-2 and S-4). The impact of reducing the border barrier at BCPs is not stable; it is larger where the freight charge is lower (the cargo volumes in these BCPs increase by around $10 \%$ from S-1 to S-2, while they increase by around $20 \%$ from S-3 to S-4). 


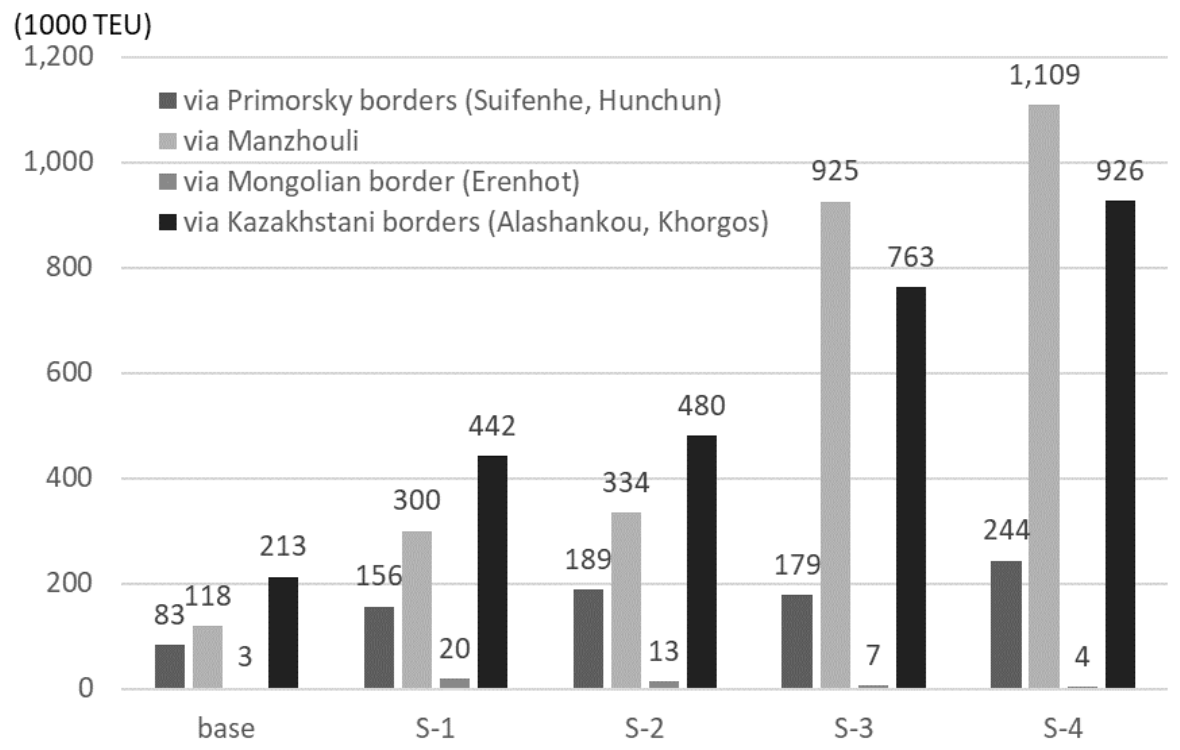

Fig. 2. Estimated cargo volume at selected land BCPs of China by scenario. Source: Authors' estimation.

\subsection{Shift from Maritime Shipping to Land Transport}

As the total volume of cargo shipping demand is fixed at the 2013 level in our model, the increased cargo volume via land borders is thought to shift from maritime shipping. Figure 3 shows the increased amount of cargo at land borders and decreased amount at seaports in China and Russian Far East. It suggests general magnitude of the shift to the transcontinental transport. In the scenario S-4, the amount of shifting from maritime shipping to land transport is around two million TEU, which is approximately equivalent to 10 percent of the actual container amount between East Asia and Europe.

In China, the decreased amount of container cargo at seaports are almost same as the increased amount of cargo at Chinese land BCPs in every scenario, which suggests that the cargo might be generally diverted from oceangoing vessels to land transport under the assumed promotion measures. Nevertheless, there are slight differences between the increased and decreased amount in each scenario. In the scenarios S-1 and S-2, the decreased amount at the seaports exceeds the increased amount at the land borders, which may be occurred by the shift for some international cargo from maritime domestic shipping to land transport in China. On the contrary, in the scenarios S-3 and S-4, the increased amount at the land borders exceeds the decreased amount at the seaports, which can be explained by emergence of land transit transport through Chinese territory, for instance from Russian Far East to Central Asia, which currently does not exist in practice. 


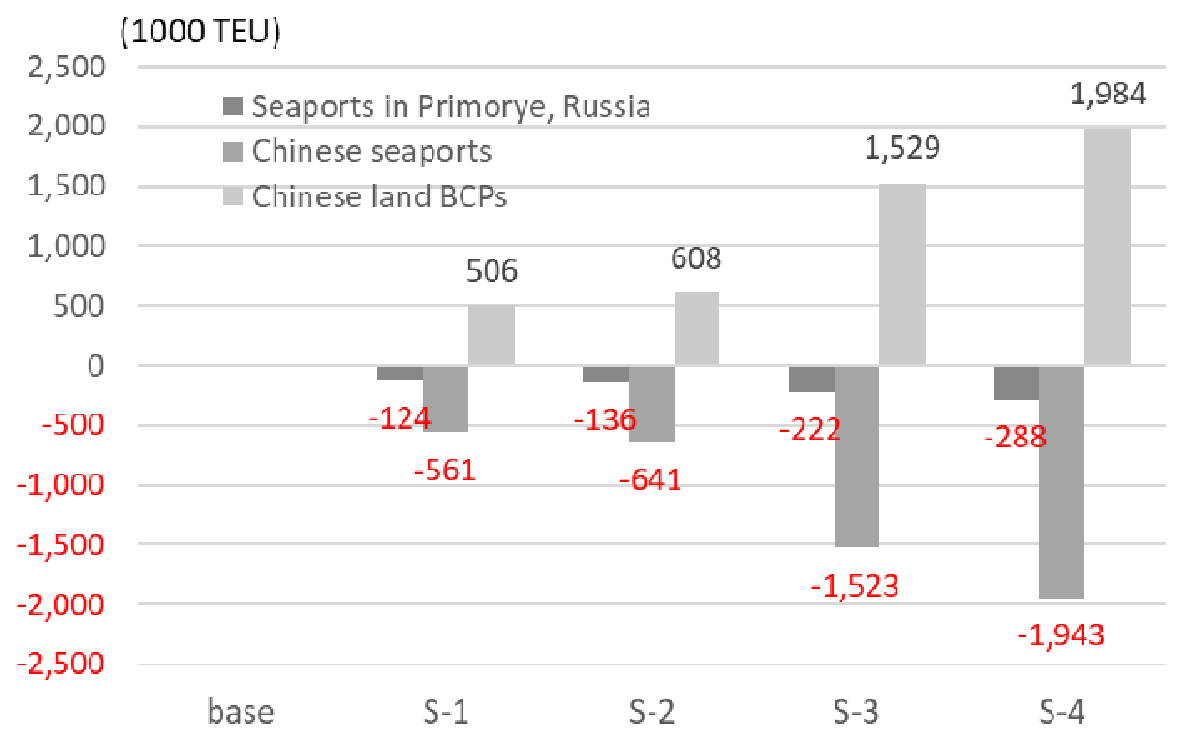

Fig. 3. Estimated change in cargo volume at seaports and land BCPs by scenario. Source: Authors' estimation.

\subsection{Impacts on Russia with a Focus on Far East}

As major transcontinental railway routes transit Russia, the cargo volumes to transit Russia are expected to increase in these scenarios by shifting from maritime shipping. The shift, however, affect differently by region of the huge country. In particular, impacts on Primorye region, a sea gateway of Russian Far East, are rather complicated, because seaports in Primorye may lose certain amount of container cargo that is currently transported from/to the Chinese coastal area.

First, the shift benefits Russia. According to Figure 2, the increased amount of cargo at the Chinese-Russian BCPs (Suifenhe, Hunchun and Manzhouli) from the baseline scenario varies from 255 (S-1) to 1152 (S-4) thousand TEU. In each scenario, the increased amount at land BCPs significantly exceeds the decreased amount at the seaports in Primorye, which is shown in Figure 3. Moreover, there are additional amount transit Russia via the ChineseMongolia and Chinese-Kazakhstan BCP.

The shift from maritime shipping to land transport in the Far East is apparent as shown in Figure 4. The figure classifies Chinese provinces in accordance with the share of land transport in the total cargo volume of a province, which are transported to Russian Far East. The area where majority of cargo is transported by land transport spreads across the whole territory of China in the scenario S-3, whereas it covers merely a few Northeastern provinces in the baseline scenario.

The simulation, however, reveals the real risk for Primorye to lose some portion of transit cargo through the changes. The increased amount at the land BCPs of Primorye shown in Figure 2 is only around 50 to 70 percent of the decreased amount at the Primorye seaports shown in Figure 3 in each scenario. 


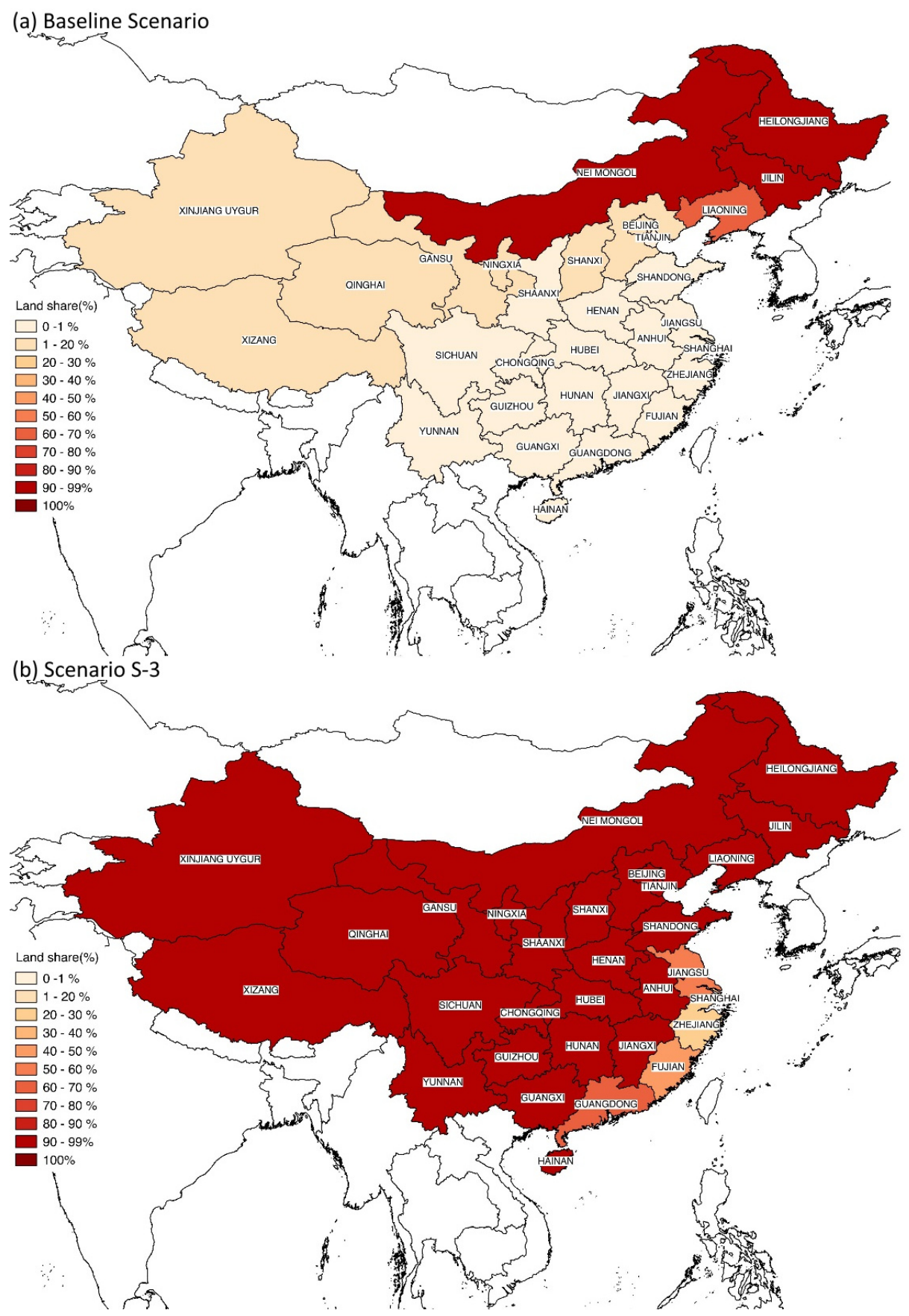

Fig. 4. Share of land transport in total cargo amount shipped from each Provinces of China to Russian Far East. Source: Authors' estimation.

The gap between the increased amount of land transport and the decreased amount of maritime shipping can be explained by possibility of a shift from maritime shipping to other land transport routes. For example, a cargo from China to western Russia, which is originally transported by maritime shipping from a China's seaport to a port in Primorye 
and then by rail to the destination, may be shifted to one of the land transport routes either via Manzhouli, Mongolia or Kazakhstan, not going through land BCPs in Primorye.

As a consequence of all these changes, as shown in Figure 5, major transport routes in the eastern part of Russia gain additional cargo volume, with an exception of great loss at the most eastern section connected to the seaports in Primorye.

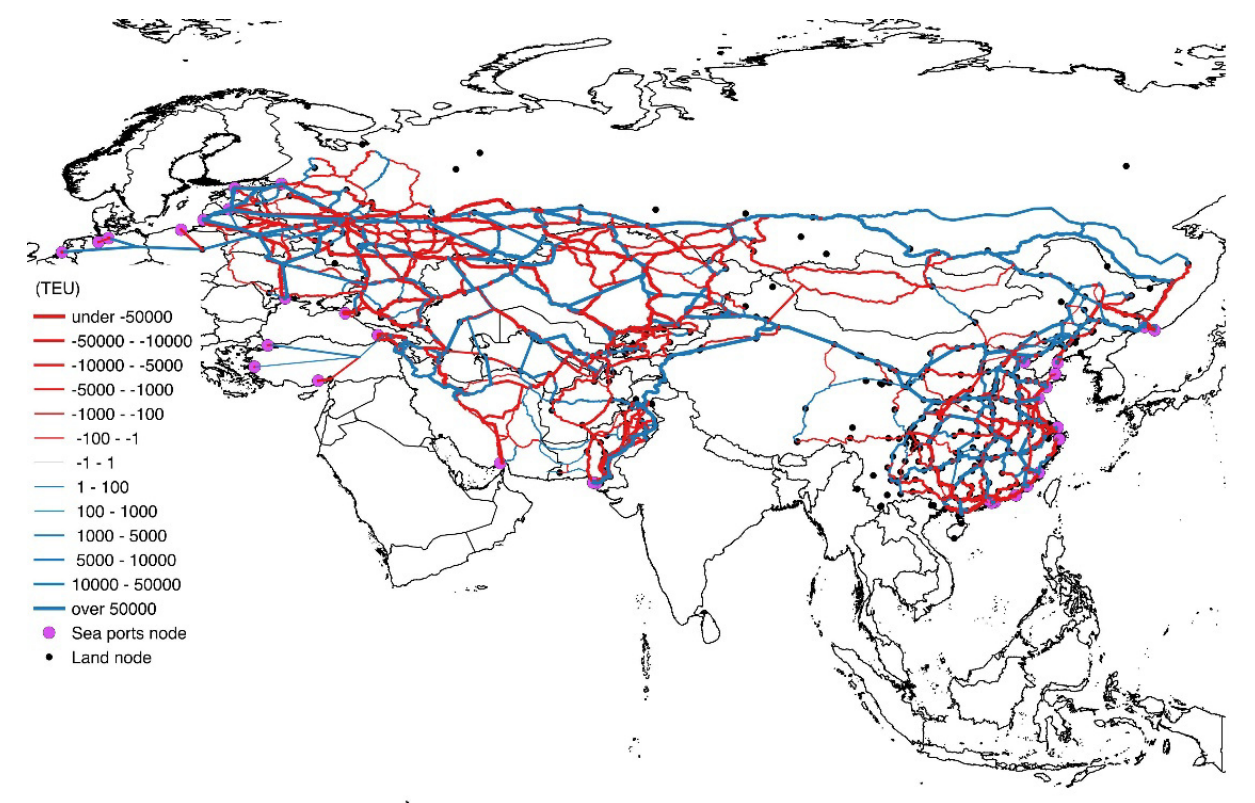

Fig. 5. Estimated change of cargo flow from the baseline scenario to the scenario S-4 by section of land transport. Source: Authors' estimation.

\section{Conclusions}

This paper argued impact of the recent strategic policies on the trans-Eurasian transport. BRI and EAEU enhance transport connectivity in the Eurasian continent, through improving infrastructure and transport services, and reducing barriers at BCPs. The enhanced connectivity increases competitiveness of land transport against maritime shipping, which should cause the shift of container cargo from maritime shipping to land transport. A question is whether the shift would fundamentally change the current balance between these transport modes. Another question is whether all countries could benefit from the changes. To answer these questions, we estimated their impacts on cargo volume using the intermodal network simulation model.

The followings are the key findings through our simulation and policy implications thereof.

First, the shift from maritime shipping would be rather modest. Under the scenarios we assume, the cargo volume shifted would be around 2 million TEU per year in maximum, which accounts for about 10 percent of the total container flows between Asia and Europe. Although the land transport has potential to increase cargo volume several times as the current level, the maritime shipping will be still a dominant mode in the intercontinental cargo transport. 
In addition, the simulation reveals that the reduction of freight charge is the most effective for attracting cargo among the promotional means examined. The current discount of rail freight charge are available owing to subsidies from the regional governments of China. The subsidies should be a short-term measure for the sake of sound development of market; it cannot be everlasting, considering the fiscal constraint. A key to further development of land transport is reducing the cost through pursing scale economy and operational optimization, which may substitute the subsidies.

In case of Russia, although the country could gain net increase in volume through the cargo shift from maritime shipping, Primorye region, a Far Eastern gateway of Russia, might lose certain amount of transit cargo. Taking into account the importance of the Far Eastern region in terms of balanced regional development of the country, the federal government should implement some counter-measures dedicated to regional transport industry.

The main contribution of our work in this chapter is to estimate the impact of the recent policies on the trans-Eurasian transport quantitatively. We hope that the outcome could promote further policy development aiming at improving connectivity under the international cooperative framework.

This work was supported by JSPS KAKENHI Grant Number JP 17 H03327.

\section{References}

1. Coordinating Council on Trans-Siberian Transportation International Association (CCTT). Annual TSR Digest 2018, CCTT (2018)

2. Coordinating Council on Trans-Siberian Transportation International Association (CCTT). Annual TSR Digest 2016, CCTT (2016)

3. Eurasian Development Bank (EDB) (Centre for Integration Studies). Silk Road Transport Corridors: Assessment of Trans-EAEU Freight Traffic Growth Potential, EDB (2018)

4. J. Jakóbowski, K. Popławski, M. Kaczmarski, The Silk Railroad - The EU-China rail connections: background, actors, interests (OSW Studies 72). Cent. for East. Stud. (2018)

5. R. Shibasaki, T. Iijima, T. Kawakami, T. Kadono, T. Shishido, Network assignment model of integrating maritime and hinterland container shipping: application to Central America. Maritime Econ. \& Log. 19(2), 234-273 (2017)

6. R. Shibasaki, T. Kawasaki, International intermodal container shipping network in South Asia: Modelling and policy simulations. Intern. J. of Shipp. and Transp. Log.

7. R. Shibasaki, K. Nishimura, S. Tanabe, H. Kato, How Does China's BRI Encourage the Use of International Rail Transport across the Eurasian Continent? An Approach By Intermodal Logistics Network Assignment Model. In: 7th Intern. Conf. on Transp. and Log., Dalian, China (2018) 